
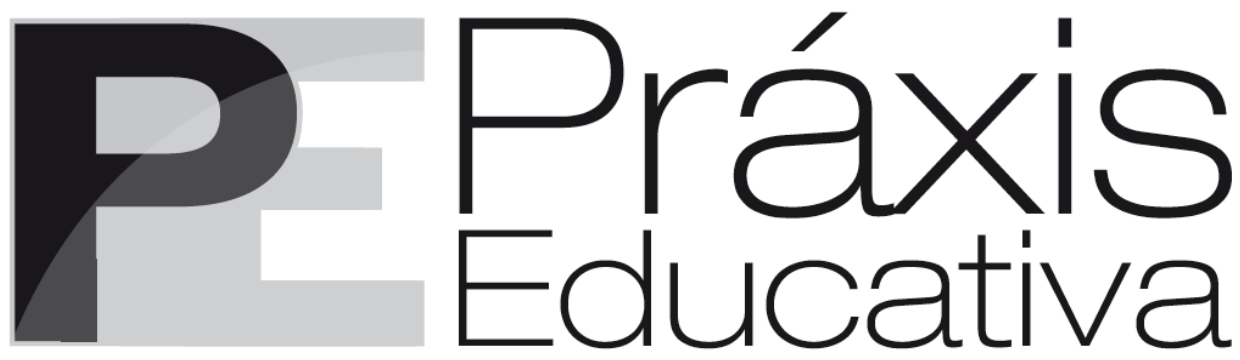

ISSN 1809-4031

elSSN 1809-4309

https://doi.org/10.5212/PraxEduc.v.16.17601.038

Resenha

\title{
CAMPOS, Névio de; MONTANER, Gerardo Garay. (org.). Os intelectuais em contextos nacionais e internacionais: campos, fronteiras e disputas. Porto Alegre: Editora Fi, 2021. 461 p.
}

Jaine dos Santos Floriano* https://orcid.org/0000-0002-5345-882X

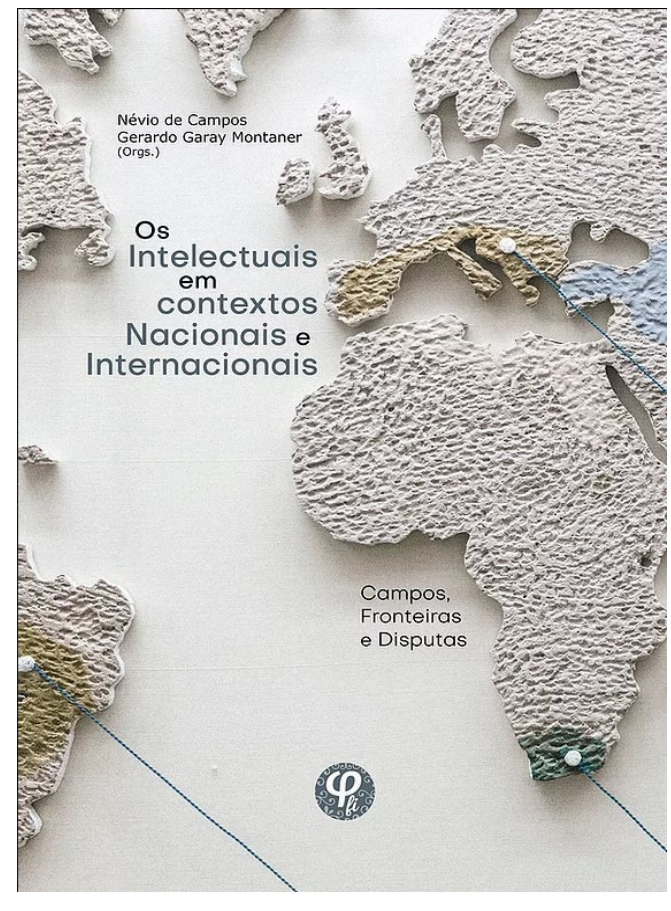

A obra Os intelectuais em contextos nacionais e internacionais: campos, fronteiras e disputas, organizada por Névio de Campos e Gerardo Garay Montaner, é resultado dos estudos do grupo de pesquisa "História, Intelectuais e Educação no Brasil e no contexto internacional", formado por pesquisadores da Universidade Estadual de Ponta Grossa (UEPG), Universidade Estadual do Paraná (Unespar) e Universidade da República do Uruguai (Udelar). O livro contém artigos de professores, de mestrandos, de doutorandos e de egressos. O resultado desse trabalho também diz respeito ao intercâmbio com a Escola de Altos Estudos em Ciências Sociais (EHESS) e com o Centro Europeu de Sociologia e de Ciência Política (CESSP), localizados na França, onde o pesquisador Névio de Campos desenvolveu seu Pós-doutorado sob a supervisão de Giséle Sapiro.

O livro está organizado em 16 capítulos, divididos em quatro partes, nas quais os autores tecem considerações e discutem temas relacionados aos Intelectuais. Essa temática ganhou força no contexto francês no final do século XIX, com o caso Dreyfus. Desse modo, se, por um lado, a discussão acerca dos intelectuais está fortemente ligada ao contexto francês, como pode ser percebido nos primeiros capítulos desse livro; por outro, existe uma expansão desse campo de estudo, o qual remete a diferentes contextos e períodos da história, e a ampliação do conceito de

\footnotetext{
* Doutoranda do Programa de Pós-Graduação em Educação da Universidade Estadual de Ponta Grossa (UEPG). Professora colaboradora do Departamento de Educação da UEPG. E-mail: <jaine.f@hotmail.com>.
} 
CAMPOS, Névio de; MONTANER, Gerardo Garay. (org.). Os intelectuais em contextos nacionais...

intelectual e seu campo de atuação. Nesse sentido, o livro é composto por diferentes contextos históricos e geográficos, o qual abarca experiências europeias, brasileiras e uruguaias durante o século XX.

A primeira parte do livro - Intelectuais e as fronteiras do campo intelectual - é composta por quatro capítulos, os quais partem do geral em direção ao particular. O Capítulo 1 considera o campo intelectual em debates de internacionalização, e o Capítulo 2 revela como essa internacionalização ocorreu no Brasil por meio das missões francesas. Na sequência, surgem dois textos que dizem respeito a questões mais locais: o terceiro capítulo, o qual discorre sobre a questão intelectual no Uruguai na década de 1960; e, por fim, o quarto capítulo que aborda a trajetória de um intelectual regional. Desse modo, pode-se observar a relação entre os dados empíricos e as dimensões do campo intelectual no âmbito internacional e nacional.

O Capítulo 1, escrito por Gisele Sapiro e traduzido por Névio de Campos, denominado Internacionalização dos campos intelectuais no periodo entre as duas guerras mundiais: fatores profissionais e politicos, versa sobre o período da segunda metade do século XIX e do início do século XX, o qual marcou a internacionalização da vida intelectual, propiciada pela organização profissional e por políticas internacionais, com destaque ao contexto europeu, especialmente à França. A autora destaca que, embora a ideia de intelectuais tenha nascido com o Caso Dreyfus, foi no contexto entre as duas Guerras Mundiais que se operou uma mobilização política em larga escala em torno das questões internacionais. É nesse contexto que se constituiu um espaço de intercâmbio formal de base nacional e que, em contrapartida, se formou um espaço de representações culturais e geopolíticas no âmbito internacional, com vistas à construção de uma comunidade mundial dos intelectuais.

No Capítulo 2 - Missão Francesa na USP e internacionalização do campo científico -, Névio de Campos dá sequência ao tema ao retomar as principais ideias postas por Sapiro. Nesse texto, Campos discorre sobre as relações entre o Brasil e a França no início do século XX e apresenta a experiência da missão francesa na Faculdade de Filosofia, Ciências e Letras da Universidade de São Paulo (USP), a qual possuía um caráter institucionalizado, originário das universidades e das grandes escolas francesas, cujo foco era a propagação de uma comunidade científica internacional. $\mathrm{O}$ autor ainda destaca que as missões universitárias estavam perpassadas pelos interesses políticos franceses em meio às disputas internacionais entre os países europeus e demonstra a relação entre ciência e política no movimento de internacionalização do campo intelectual e científico.

No Capítulo 3 - Intelectuales y política en la década del 60: anotaciones sobre la "generación crítica"-, Antonio Romano discute o papel dos intelectuais na esfera pública no Uruguai, durante a década de 1960, a qual ficou conhecida como geração crítica. Segundo o autor, há certo consenso em considerar que a cultura da época foi assinalada pela consciência crítica, sendo essa geração formada por um grupo de pensadores que incluía desde políticos até educadores, originários da classe média. Romano aponta que essa geração foi marcada pela experiência da crise no país, por isso seu compromisso seria compreender as causas que levaram à crise, de forma a propiciar uma consciência política. Seriam então os intelectuais os representantes da cultura em um país pobre e em crise, os quais faziam uma releitura de sua própria história como grupo e distanciavam-se do poder político.

O Capítulo 4, que finaliza a primeira parte do livro, intitulado Jacob Holzmann: um intelectual mediador no interior do Brasil nas primeiras décadas do século XX, escrito por Ana Flávia Barboza Garcia e Maria Julieta Weber Cordova, é resultado de pesquisa de Garcia (2019). O texto analisa a trajetória e as contribuições de um intelectual regional, com base nas ações culturais desenvolvidas por ele. Holzmann era filho de um imigrante russo-alemão e viveu em um período em que Ponta Grossa começava a crescer e a se destacar devido ao entroncamento ferroviário, em busca de modernizar-

Práxis Educativa, Ponta Grossa, v. 16, e2117601, p. 1-6, 2021

Disponível em: <https://www.revistas2.uepg.br/index.php/praxiseducativa> 
se com vistas a ser reconhecida por seu progresso. Nesse contexto, Holzmann podia ser considerado uma personificação da mediação cultural, visto que propiciava que a população da cidade tivesse contato com um novo cotidiano cultural, por meio da Banda Lyra dos Campos, do Cine Theatro Renascença e do jornal O Progresso (posteriormente denominado Diário dos Campos). Dessa forma, trata-se de um intelectual mediador, o qual se valeu da rede de sociabilidades já estabelecidas por sua família na sociedade ponta-grossense, e que, apesar de ter escrito pouco, esteve inserido em diferentes meios de atuação cultural, social e política.

A segunda parte do livro - Intelectuais e Estado -, composta também por mais quatro capítulos, conforme o próprio nome já sugere, diz respeito a diferentes formas de interação entre os intelectuais e o Estado, e mostra diversificadas formas de estratégia, de comportamento e de relacionamento com os agentes do campo político. Nesse sentido, no Capítulo 5 - O ensino religioso e a laicidade nas escolas públicas do Brasil nos debates do Supremo Tribunal Federal (2017-2018) - , Federico Alvez Cavanna, ao analisar um caso recente no país sobre o ensino religioso nas escolas públicas, mostra como os debates no Supremo Tribunal Federal (STF), sobre o conceito de laicidade, são perpassados pelas formas hegemônicas de ver a escola, de modo a demonstrar como uma palavra permeada por um campo semântico amplo e impreciso pode ter diferentes significados e afetar, assim, os campos judiciário, educacional, político e social. O debate sobre laicidade e ensino é antigo no Brasil e tem posições antagônicas na disputa pelo poder, cujo resultado da decisão demonstra uma privatização do ensino público e nega a sua alteridade.

No Capítulo 6, denominado Relaçoes de Flávio Suplicy de Lacerda com as Forças Armadas no Brasil, Eliezer Felix de Souza, a partir de um recorte de sua tese de Doutorado (SOUZA,2016), reflete sobre a trajetória do intelectual Flávio Suplicy de Lacerda, o qual se destacou como reitor da Universidade Federal do Paraná (UFPR) de 1949 a 1971, por federalizar e trabalhar para a sua expansão. No campo político, caracterizou-se como conservador, articulado com a elite intelectual paranaense e foi nomeado ministro da Educação no primeiro Governo da Ditatura Civil-Militar em 1964. Nesse cargo, ele se destacou por elaborar normatizações com penas severas aos estudantes com atuação política. Essa relação com o Governo pode fazer com que ele seja entendido como um guardião da ordem, o qual ajudou a instituir práticas autoritárias. O texto propicia aos leitores a compreensão de como se configura um intelectual institucional ou de organização política.

No Capítulo 7 - Fernando de Arevedo e a educação pública no Brasil -, Breno Pereira Machado, baseado em sua dissertação de Mestrado (MACHADO, 2018), buscou apresentar o conceito de educação pública para o pensador Fernando de Azevedo, com base no debate ocorrido tanto no Brasil quanto na França, durante os séculos XVIII e XIX. Azevedo, o qual se destacou no campo educacional e político, buscou realizar reformas na educação pública, pois ele a via como um problema quando esta deveria ser um instrumento para o progresso nacional. O texto analisa, em um primeiro momento, as contribuições de Condorcet, Le Peletier e Jules Ferry no âmbito educacional, com vistas à necessidade de implantação de um sistema educacional público, para, na sequência, expor o debate sobre a educação pública no Brasil, segundo o pensamento de Fernando de Azevedo, com base na tradição francesa. Representante do Movimento da Escola Nova, Azevedo foi responsável por reformas, debates, campanhas e inquéritos educacionais e defendia a organização de um sistema de ensino público, gratuito e laico.

Na sequência, Natália Cristina de Oliveira recorreu à sua tese (OLIVEIRA, 2018) para escrever o Capítulo 8, intitulado Padre Leonel Franca e o Ensino Superior Católico no Brasil. Nele, a autora destaca a trajetória desse intelectual católico, em um contexto de disputa pelo poder da Igreja Católica durante o Governo Vargas. Padre Leonel Franca se destacou como o principal responsável por articular as relações entre a Igreja Católica e o Governo, o inserir-se no campo educacional 
CAMPOS, Névio de; MONTANER, Gerardo Garay. (org.). Os intelectuais em contextos nacionais...

com ênfase na instrução e na religiosidade. Vale destacar que os intelectuais católicos defendiam que a crise moral instalada no Ocidente era decorrente do afastamento do homem aos ensinamentos da Igreja, e, por isso, defendiam o ensino religioso como forma de restaurar os valores cristãos. Além disso, utilizavam a impressa, como é o caso da revista $A$ Ordem, para propagar esse ideário. Nesse sentido, consideravam a educação como uma das áreas mais estratégicas para a atuação cultural e espiritual. Destaca-se, também, a criação das faculdades católicas como forma de perpetuar esse ideário por meio da formação docente. Segundo a autora, o Padre Leonel Franca aproveitou a representação que tinha como porta-voz da Igreja Católica para deslocar-se pelo campo político e para conquistar o campo educacional, tornando-se um dos intelectuais católicos que, na primeira metade do século XX, atuou de forma mais intensa nos campos político e social.

$\mathrm{Na}$ terceira parte do livro, composto por mais quatro capítulos, discute-se a relação entre Intelectuais e Igreja Católica. Demonstra-se como essa instituição cooptou diferentes intelectuais, desde o clero até o laicato católico, como estratégia de alcançar seus objetivos na disputa pelo poder. Para isso, no Capítulo 9, intitulado Intelectuais católicos e o advento republicano: a presença de clérigos e leigos como fundamento e meio de ação da igreja romana no Brasil, Oriomar Skalinski Junior discute a relação entre a hierarquia da Igreja e o laicato no período republicano, no intuito de verificar o impacto cultural de tal intervenção, de analisar algumas cartas pastorais e de destacar a ação de intelectuais leigos no projeto de romanização da Igreja. Conforme aponta o autor do capítulo, intelectuais como Dom Sebastião Leme, Jackson Figueiredo e Alceu Amoroso Lima difundiram e fortaleceram um repertório simbólico e conceberam uma apropriação católica do advento da República.

No Capítulo 10 - Intelectuales católicos en Uruguay en la segunda mitad del siglo XX: presencia y relaciones con los frailes dominicos de Toulouse -, Susana Monreal busca compreender as experiências intelectuais vinculadas aos frades da Província de Toulose. A autora discute como estes buscaram estreitar as relações entre o mundo secular e a Igreja Católica ao instalarem-se em Montevidéu. Segundo a autora, a comunidade dominicana funcionou nessa cidade entre 1953 e 1970, bem como apoiou e promoveu iniciativas no campo intelectual. Esses frades dominicanos tinham diversos níveis acadêmicos, oriundos das universidades francesas e estavam vinculados a uma renovação teológica que vinha ocorrendo na Europa. Durante quase 20 anos, os frades dominicanos realizaram projetos culturais e acompanharam os intelectuais católicos locais, de forma a promover diferentes linhas de pensamento no campo da Sociologia, da História e da Filosofia. O trabalho dos frades marcou a história regional e expandiu-se para outros países da América Latina, por meio de experiências evangelizadoras durante várias décadas.

Bianca Neves Prachum, com base em um recorte de sua dissertação de Mestrado (PRACHUM, 2019), apresenta o Capítulo 11, denominado Everardo Backheuser e a pedagogia nova católica no Brasil, em que a autora descreve a trajetória intelectual de Everardo Backheuser e analisa sua relação com a educação católica. No texto, a autora apresenta suas contribuições para a Pedagogia Nova Católica no Brasil com base em seus manuais pedagógicos. Em um contexto marcado pela disputa entre os católicos e os pioneiros da Educação Nova, Everardo Backheuser buscou defender os ideais dos católicos ao adaptar as ideias que considerava coerentes com as dos pioneiros da Educação Nova. Sua produção intelectual contribuiu com uma nova proposta de Pedagogia católica no país, pois sua atuação fazia parte de uma estratégia em conjunto com outros intelectuais católicos.

Na sequência, no Capítulo 12 - Dom Hélder Câmara e as novas direções da Igreja Católica no Brasil (1952-1964) -, Marieli de Oliveira Ávila apresenta a trajetória desse intelectual católico, bem como analisa o impacto de suas ações em relação à Igreja Católica de 1952 a 1964. A autora aponta que a vida de Dom Hélder Câmara foi marcada pela defesa da igreja e dos seus ideais. Ele ficou

Práxis Educativa, Ponta Grossa, v. 16, e2117601, p. 1-6, 2021

Disponível em: < https://www.revistas2.uepg.br/index.php/praxiseducativa> 
conhecido pela Cruzada São Sebastião, a qual buscava resolver o problema da moradia nas favelas do Rio de Janeiro, para propiciar aos pobres uma vida mais digna e cristã. Por meio de seu trabalho religioso e social, Dom Hélder Câmara conseguiu atrair mais pessoas para a sua causa. Foi, assim, um intelectual importante por provocar mudanças e reflexões na igreja e aproximá-la da pauta dos mais pobres.

$\mathrm{Na}$ última parte do livro - Intelectuais e intervenção política -, formada por outros quatro capítulos, os autores discutem questões como gênero, direitos humanos e concepções de educação. No Capítulo 13, intitulado José Rodrigues Vieira Netto: o discurso proibido sobre as quatro liberdades e a defesa dos direitos humanos na ditadura militar, Regis Clemente da Costa, a partir de sua tese de Doutorado (COSTA, 2018), apresenta as contribuições de Vieira Netto para a defesa dos direitos humanos, com base em sua obra Sobre as quatro liberdades, texto censurado pela ditadura militar. Vieira destacou-se, no meio jurídico, como advogado e professor, como político e atuante nos movimentos sociais. Sua obra foi escrita em ocasião da formatura da turma de Direito da UFPR no ano de 1964, quando foi impedido de falar como paraninfo. Vieira atuou como agente político e seu trabalho não se esgotou no conhecimento científico. Ele foi reconhecido por seu papel de intelectual na organização da cultura, a qual partia da concepção gramsciana de intelectual orgânico.

No Capítulo 14 - Escuela antidogmática y lucha contra la ignorancia: intelectualidad obrera y magistério en la primera mitad del siglo XX, Uruguay -, Gerardo Garay Montaner realizou uma investigação sobre acontecimentos cotidianos descritos no Libro Diario Escolar de la Escuela Experimental de Progreso, no período de 1929 a 1942. Niemann, diretor dessa escola, escreveu mais de duas mil páginas, nas quais narrou os acontecimentos que considerava relevantes na escola. Ele abrangeu temas diversos como seus sentimentos, a aplicação do método Decroly e a incompreensão de algumas famílias sobre a organização da escola. Seu trabalho tinha como objetivo elevar a cultura no meio rural e promover a escolarização de trabalhadores, sendo responsável por um empreendimento coletivo na figura de diretor.

Outra contribuição importante está no Capítulo 15 - Mariana Coelho e sua atuação no campo intelectual paranaense e brasileiro -, em que Dyeinne Cristina Tomé, a qual traz um recorte de sua tese de Doutorado (TOMÉ, 2020), apresenta as ações da escritora e intelectual paranaense Mariana Coelho junto ao campo intelectual regional e nacional entre o final do século XIX e a primeira metade do século XX, especialmente no que tange às questões feministas, quando estabeleceu vínculo com a líder feminista Bertha Lutz. Por meio de seus escritos, Mariana buscava educar suas leitoras, e, assim, consagrou-se como uma das primeiras intelectuais feministas paranaenses. Ela atuou nos campos cultural, social e literário.

No último capítulo do livro, denominado Debates sobre o voto feminino na imprensa: uma pauta internacional nas páginas do Diário dos Campos - Ponta Grossa, Paraná -, Karina Regalio Campagnoli analisa algumas reportagens sobre o voto feminino no Diário dos Campos, de 1920 a 1934 e de 1932 a 1937. No texto, resultado de sua dissertação de Mestrado (CAMPAGNOLI, 2020), a autora reflete sobre os contextos de lutas e de conquistas femininas. É interessante notar que o jornal evidenciou diferentes posicionamentos das mulheres com relação ao tema, sendo algumas favoráveis enquanto outras eram contrárias ao direito de votar. Ela aponta como isso mostra que o gênero feminino não era um grupo coeso sobre todos os aspectos e como perpassou pela complexidade da sociedade. Campagnoli destaca, ainda, a contribuição de algumas intelectuais ponta-grossenses, como Anita Philipovsky.

O livro tem como elemento comum os intelectuais, os quais abrangem contextos nacionais e internacionais, bem como a questão de fronteiras, campos e disputas. Contudo, não há uma definição teórico-metodológica definida, pois cada capítulo possui a sua própria organização. Desse

Práxis Educativa, Ponta Grossa, v. 16, e2117601, p. 1-6, 2021

Disponível em: <https://www.revistas2.uepg.br/index.php/praxiseducativa> 
CAMPOS, Névio de; MONTANER, Gerardo Garay. (org.). Os intelectuais em contextos nacionais...

modo, o leitor interessado em aprofundar seu entendimento sobre os intelectuais encontra, nesse livro, debates muito profícuos, os quais podem levar à ampliação de horizontes e a novas pesquisas.

\section{Referência}

CAMPAGNOLI, K. R. "Da zelosa mãe e esposa à recatada professora, trabalhadora e cidadã de direitos": representações das mulheres e da sua educação no Diário dos Campos nas décadas de 1920/1930. 2020. Dissertação (Mestrado em Educação) - Universidade Estadual de Ponta Grossa, Ponta Grossa, 2020.

COSTA, R. C. da. José Rodrigues Vieira Netto: intelectual orgânico, professor brilhante, advogado perseguido, cidadão sem direitos (1945-1973). 2018. Tese (Doutorado em Educação) Universidade Estadual de Ponta Grossa, Ponta Grossa, 2018.

GARCIA, A. F. B. Trajetória de Jacob Holzmann: mediação cultural em Ponta Grossa nas primeiras décadas do século XX. 2019. Monografia (Licenciatura em História) - Universidade Estadual de Ponta Grossa, Ponta Grossa, 2019.

MACHADO, B. P. Fernando de Azevedo e o conceito de Educação Pública no Brasil. 2018. Dissertação (Mestrado em Educação) - Universidade Estadual de Ponta Grossa, Ponta Grossa, 2018.

OLIVEIRA, N. C. de. Trajetória intelectual do jesuíta Leonel Franca: educação e catolicismo (1923-1948). 2018. Tese (Doutorado em Educação) - Universidade Estadual de Ponta Grossa, Ponta Grossa, 2018.

PRACHUM, B. N. Educação e catolicismo: a construção de um modelo de professor e as apropriações católicas da Escola Nova a partir de Everardo Backheuser (1928-1946). 2019. Dissertação (Mestrado em Educação) - Universidade Estadual de Ponta Grossa, Ponta Grossa, 2019.

SOUZA, E. F. de. Flávio Suplicy de Lacerda: relações de poder no campo acadêmico/político paranaense e o processo de federalização e modernização da Universidade do Paraná (1930-1971). 2016. Tese (Doutorado em Educação) - Universidade Estadual de Ponta Grossa, Ponta Grossa, 2016.

TOMÉ, D. C. Mariana Coelho e a educação das mulheres: uma escritora feminista no campo intelectual (1893-1940). 2020. Tese (Doutorado em Educação) - Universidade Estadual de Ponta Grossa, Ponta Grossa, 2020. 